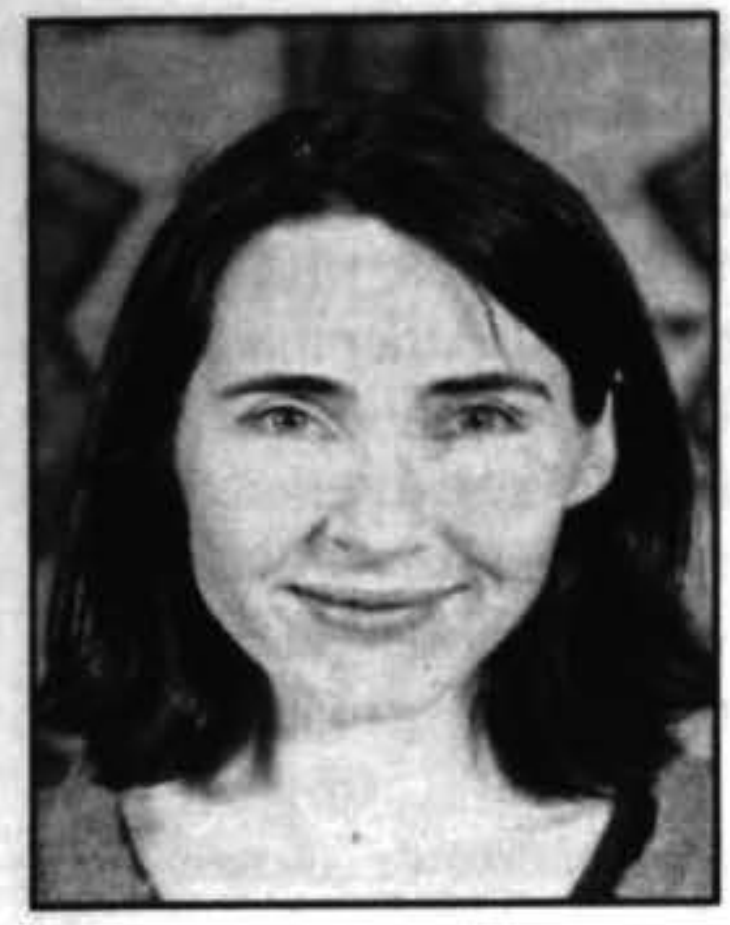

\title{
POLICY CHANGE AND PATTERNS OF DOMESTIC PURPOSES BENEFIT RECEIPT: A MULTIPLE COHORT ANALYSIS USING BENEFIT DYNAMICS DATA
}

\author{
Moira Wilson and Deborah Ball ${ }^{1}$ \\ Information and Analysis Group \\ Ministry of Social Policy
}

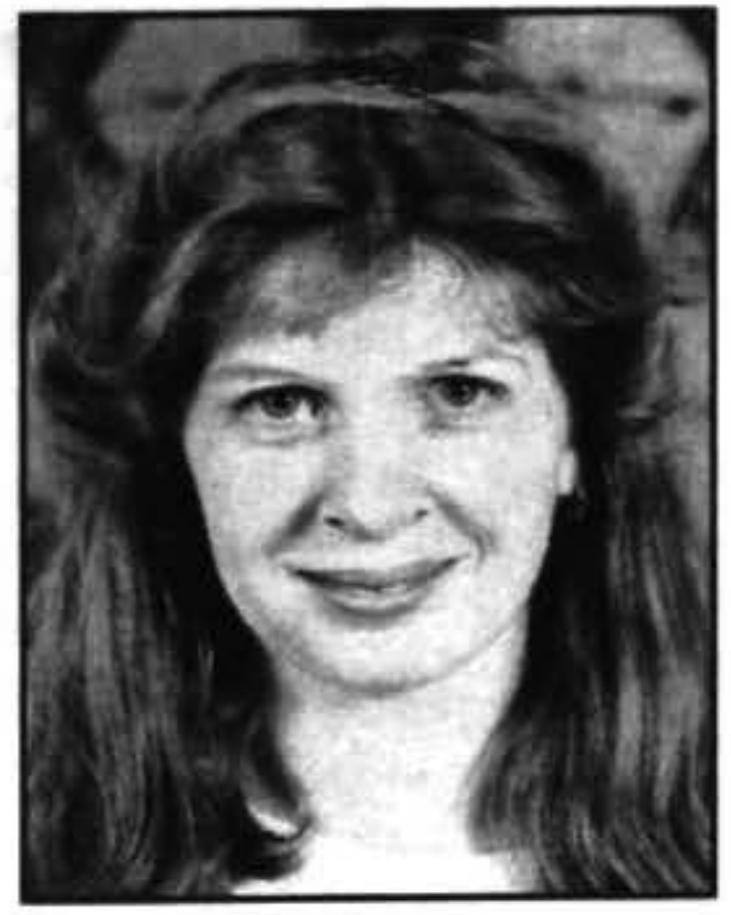

\begin{abstract}
Since 1996, the abatement regime and conditions of entitlement facing sole parents in receipt of the Domestic Purposes Benefit have changed markedly. These changes were intended to increase sole parents' likelihood of supporting themselves and their families through paid employment. Were they effective in raising levels of participation in parttime and full-time work? This paper addresses this question using a multiple cohort analysis based on administrative data on benefit dynamics. It finds marked differences in the declared earnings of successive cohorts that coincided with the 1996 and 1997 Employment Task Force reforms, and strongly suggest that those reforms increased DPB recipients participation in part-time employment. It finds no marked differences in declared earnings propensities following the 1999 DPB reforms, but marked increases in the probability of being off benefit which appear to at least partly reflect policy impacts on full-time employment propensities. It is possible that compositional changes associated with these increases mask changes in part-time employment propensities. This is an area for further work.
\end{abstract}

Keywords: Domestic Purposes Benefit, cohort analysis, dynamics, earnings

Since 1996, the abatement regime and conditions of entitlement facing sole parents in receipt of the Domestic Purposes Benefit (DPB) have changed markedly, see Table 1 . These changes were intended to increase sole parents' likelihood of supporting themselves and their families through paid employment.

\section{Table 1. DPB Policy Changes 1996 - 1999}

\begin{tabular}{|c|c|}
\hline Date & Policy Change \\
\hline 1 July 1996 & ETF Abatement change \\
\hline 1 April 1997 & $\begin{array}{l}\text { ETF Reciprocal obligations: } \\
\text { - } \quad \text { Youngest child aged 14+- } \\
\text { Part-time work test } \\
\text { - Youngest child aged 7-13- } \\
\text { Annual planning interview } \\
\text { - Youngest aged 0-6- No } \\
\text { change }\end{array}$ \\
\hline
\end{tabular}

1 February DPB Review Reciprocal 1999
Did these policy changes result in increased levels of participation in part-time and full-time work? This paper provides an in-depth picture of what happened to successive cohorts of sole parent DPB entrants as they moved through the reforms provides a tentative assessment of the extent to which changes in patterns of receipt might reflect policy impacts.

\section{Policy Change 1996-1999}

As part of the response to the Employment Task Force (ETF), a new abatement regime which offered greatly improved financial incentives to combine DPB receipt with part-time employment was introduced (Table 2). From I July 1996 the income threshold beyond which the main benefit began to abate was increased and the abatement rate applying for the first $\$ 100$ weekly income above this threshold was substantially reduced.

Table 2. Abatement Rates Applying to DPB

\begin{tabular}{lcc}
\hline $\begin{array}{l}\text { Income level } \\
\text { (\$ per week) }\end{array}$ & $\begin{array}{c}\text { Abatement rate applying to DPB } \\
\text { Before 1 July } \\
1996 \%\end{array}$ & $\begin{array}{c}\text { From 1 July } \\
\mathbf{1 9 9 6} \%\end{array}$ \\
\hline$\$ 0-60^{*}$ & 0 & 0 \\
$\$ 61-80$ & 30 & 0 \\
$\$ 81-180$ & 70 & 30 \\
$\$ 181$ or over & 70 & 70 \\
\hline
\end{tabular}


These improved financial incentives were matched by the introduction of 'reciprocal obligations' for some groups of sole parents receiving DPB, with provision for exemption: those with a youngest child aged 14 or over became subject to a part-time work or training test; and those with a youngest child aged 7-13 who had received DPB continuously for at least a year were required to attend an annual planning interview.

These requirements were gradually rolled out to existing recipients in the year from April 1997. The work test applied to new applicants from that date. The aim of the changes was to increase DPB recipients' participation in part-time employment, and raise awareness of opportunities for education and training, as a means of improving their chances of full-time employment and independence from benefit income in the longer term.

In May 1998, changes flowing from the 1997/98 DPB Review were announced. Key among these were further changes to reciprocal obligations and abatement for sole parents receiving DPB. From 1 February 1999, reciprocal obligations began to be newly rolled out to some groups and strengthened for others, with provision for deferral. The work test applying to those with a youngest child aged 14 or over was strengthened to require participation in or search for full-time work, and those with a youngest child aged 6 to 13 became subject to a part-time work test. Those with a youngest child aged under 6 who had received DPB continuously for at least a year were required to attend an annual planning interview, and those with a youngest child aged 5 could be required to undertake activities in preparation for the part-time work test.

Those with a youngest child aged 14 or over subject to the new full-time work test became once again subject to an abatement regime that encouraged full-time rather than part-time work. This change was rolled out gradually as existing recipients came up for annual renewal and became subject to the full-time work test, and was applied to new full-time work tested recipients as they came onto benefit. In cases where the work test was deferred, the recipient remained subject to the part-time abatement regime.

\section{Data and Method of Analysis}

We apply a 'multiple cohort analysis' to benefit dynamics data to contrast the experiences of cohorts of sole parents as they passed through the period of the reforms.

Benefit dynamics data is administrative data taken from the Department of Work and Income payments system, SWIFTT, and reassembled so that it is possible to look at individual benefit histories. One of the advantages of this data is that captures the entire population of benefit recipients. The current analysis covers all people who entered DPB over the study period and is not subject to sampling error.
A multiple cohort analysis has some advantages over time series analysis as a means of exploring the possible effects of policy reforms. One of the uncertainties when considering time series data is the extent to which changes in the composition of the population, rather than changes in policy settings, account for any changes observed. By following a cohort of individuals through a period of policy reform, we can be sure that any change in the experiences of the cohort is not the result of changes in its composition, other than those that result from the ageing of its members.

In addition, by following several cohorts we can tentatively assess the possible impact of a reform by comparing the change in experiences for a cohort that has passed the date at which a reform was introduced with that for an earlier cohort that reached the same 'age' (or, in the case of this analysis, the same duration from entry) prior to the reform. Any 'difference in differences' observed might reflect the impact of the reform. Such an assessment can only be tentative, however, because the contrasting experiences of successive cohorts might also reflect: differences in their composition (consistent with the demographic shifts in the sole parent population highlighted by Goodger and Larose (1999), later cohorts of entrants, for example, have a greater representation of those with older children and may be more likely to have moved into employment by a given duration from entry). They also reflect differences in the rate at which they 'mature' (later cohorts might be more likely to enter benefit having worked in the past and may as a result move into employment when their children are younger) or differences in the wider policy, economic, or social environment faced by the cohorts at a given duration from entry.

Table 3 shows the size and composition of the seven cohorts of sole parent DPB entrants that are the subject of the analysis. The remainder of this paper examines differences in the benefit experiences of these cohorts discusses the extent to which these might be consistent with the impacts of the abatement and reciprocal obligations changes introduced since 1996.

\section{Changes in Participation in Part-time Employment}

In the absence of more direct measures, data on the earnings declared by benefit recipients provide the best proxy for participation in part-time employment by benefit recipients. Figure 1 shows the proportion of cohort members in receipt of DPB who declared earnings at quarterly intervals from 31 December 1993 to 30 June 2000. Figure 2 presents the same data in a way that allows the contrasting experiences of cohorts to be more easily distinguished, and the possible links with policy changes to be explored.

\section{July 1996 - Abatement Change}

A clear change in the likelihood of declaring earned in- 
Table 3. Size and Composition of Sole Parent DPB Entry Cohorts, 1993-1999

\begin{tabular}{lccccccc}
\hline & 1993 & 1994 & 1995 & 1996 & 1997 & 1998 & 1999 \\
\hline Number in entry cohort & 30597 & 32311 & 34210 & 34300 & 31719 & 30598 & 30143 \\
& & & $\begin{array}{c}\text { Percentage of cohort } \\
\text { con }\end{array}$ & \\
\hline
\end{tabular}

\section{Sex}

\section{Female}

Male

Ethnicity

Unknown

Ethnic composition of those for whom known

NZ Maori

$\mathrm{NZ}$ and Other European

Pacific People

Other

Age at entry

Under 20

20-29

30-39

40-49

50 or over

Previously partnered?

No

Yes

Number of children at entry

1
$3+$

Age of youngest child at entry

Under 7

7-13

14 or over

Benefit receipt in year prior to entry

Received DPB

Received any benefit as primary

Received any benefit as partner

Received any benefit as primary or partner

\section{Reason for grant at entry}

Ceased work

Separated from partner

Child came into care

Transfer from another benefit

Other/not recorded

\begin{tabular}{ccccccc}
89 & 88 & 87 & 87 & 87 & 87 & 88 \\
11 & 12 & 13 & 13 & 13 & 13 & 12 \\
& & & & & & \\
18 & 15 & 8 & 4 & 5 & 5 & 6 \\
& & & & & & \\
35 & 35 & 35 & 34 & 34 & 34 & 34 \\
54 & 53 & 53 & 53 & 53 & 53 & 52 \\
9 & 9 & 9 & 10 & 9 & 9 & 9 \\
2 & 3 & 3 & 3 & 4 & 4 & 4 \\
& & & & & & \\
10 & 10 & 10 & 10 & 10 & 10 & 10 \\
46 & 46 & 45 & 43 & 42 & 41 & 41 \\
34 & 34 & 34 & 36 & 35 & 36 & 36 \\
9 & 9 & 10 & 10 & 11 & 12 & 12 \\
1 & 1 & 1 & 1 & 1 & 1 & 1 \\
& & & & & & \\
30 & 27 & 28 & 28 & 29 & 28 & 28 \\
70 & 73 & 72 & 72 & 71 & 72 & 72 \\
& & & & & & \\
56 & 56 & 56 & 56 & 57 & 56 & 55 \\
27 & 27 & 27 & 27 & 26 & 26 & 27 \\
17 & 17 & 17 & 17 & 17 & 18 & 18 \\
& & & & & & \\
79 & 79 & 78 & 77 & 77 & 75 & 75 \\
16 & 16 & 17 & 18 & 19 & 20 & 20 \\
5 & 5 & 5 & 5 & 5 & 5 & 4 \\
& & & & & & \\
- & 25 & 25 & 25 & 24 & 27 & 28 \\
- & 56 & 57 & 56 & 56 & 56 & 56 \\
- & 26 & 23 & 21 & 20 & 22 & 23 \\
- & 70 & 68 & 66 & 65 & 66 & 66 \\
10 & 10 & 11 & 12 & 12 & 12 & 13 \\
53 & 51 & 49 & 49 & 47 & 48 & 48 \\
14 & 12 & 11 & 12 & 12 & 11 & 11 \\
11 & 16 & 17 & 16 & 17 & 17 & 16 \\
12 & 12 & 12 & 12 & 12 & 12 & 13 \\
\hline $\mathbf{1 0 0}$ & $\mathbf{1 0 0}$ & $\mathbf{1 0 0}$ & $\mathbf{1 0 0}$ & $\mathbf{1 0 0}$ & $\mathbf{1 0 0}$ & $\mathbf{1 0 0}$ \\
\hline & & & & & &
\end{tabular}

come can be observed following the 1 July 1996 policy change. Comparing the first three cohorts in Figure 2 at the same number of quarters from the end of the year of their entry, it is clear that up to 30 June 1996 (quarter 10 for 1993 entrants, quarter 6 for 1994 entrants, and quarter 2 for 1995 entrants) they tracked one another closely. After 30 June 1996, each had a much higher earnings propensity than the cohort that preceded it had at the same number of quarters from entry. Cohort-on-cohort differences peaked at around three percentage points at 30 June 1997 (an increase of 22\%). At this point each cohort had faced the new abatement for a full year while the preceding cohort, at the same number of quarters from entry, was yet to become subject to the new regime. Towards the end of the study period, the three cohorts again tracked one another more closely.

The 1996, 1997, 1998 and 1999 cohorts entered the follow-up window after the introduction of the part-time abatement regime. At quarter 0 (31 December of their year of entry), these cohorts had earnings propensities averaging 15 percent, five percentage points higher than 
Figure 1. Percentage of Cohort Members on DPB Declaring Earned Income at Quarterly Intervals (Calendar Time), 1993-1999 Sole Parent Entry Cohorts

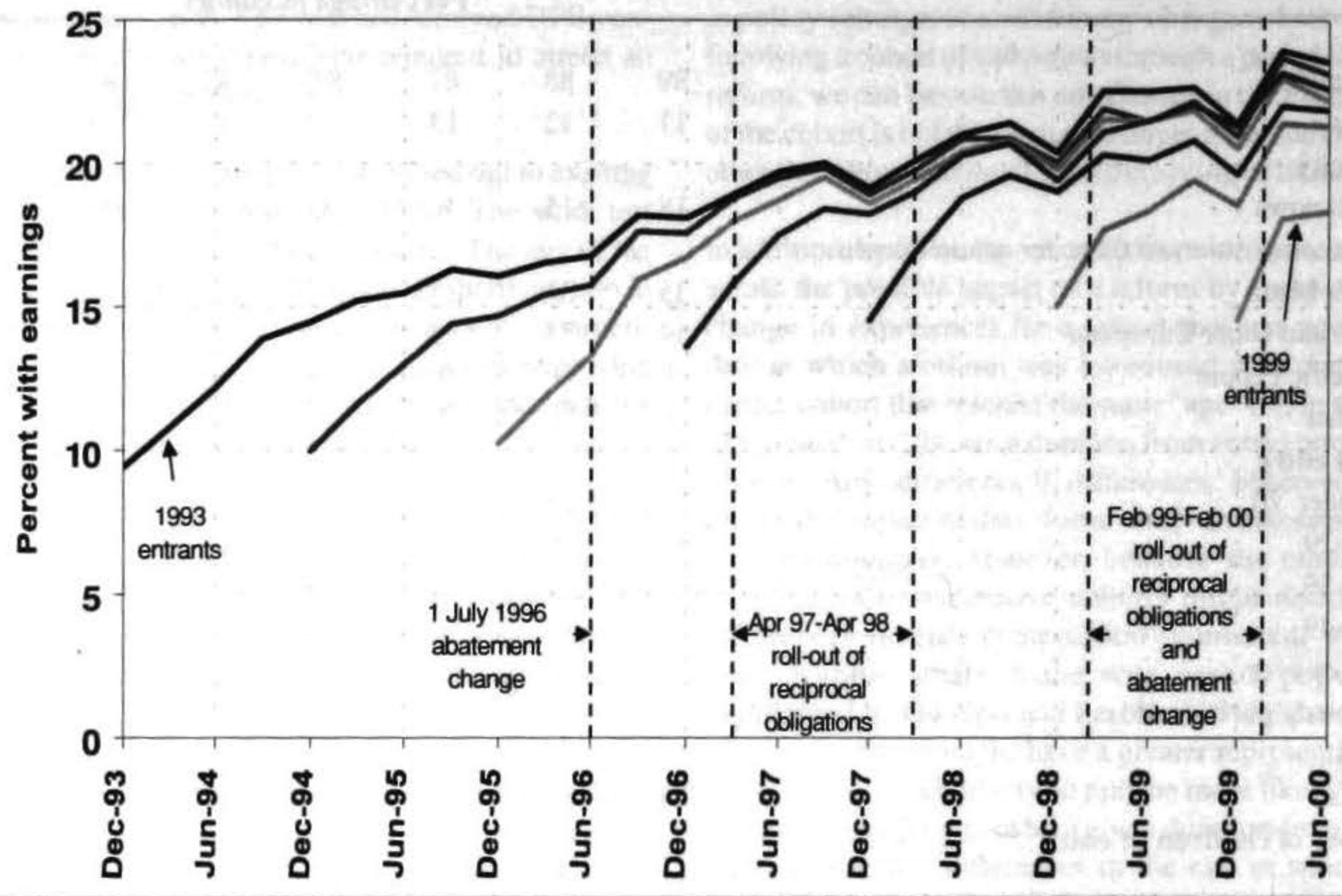

Figure 2. Percentage of Cohort Members on DPB Declaring Earned Income at Quarterly Intervals (Relative to 31 December of Entry Year), 1993, 1999 Sole Parent Entry Cohorts

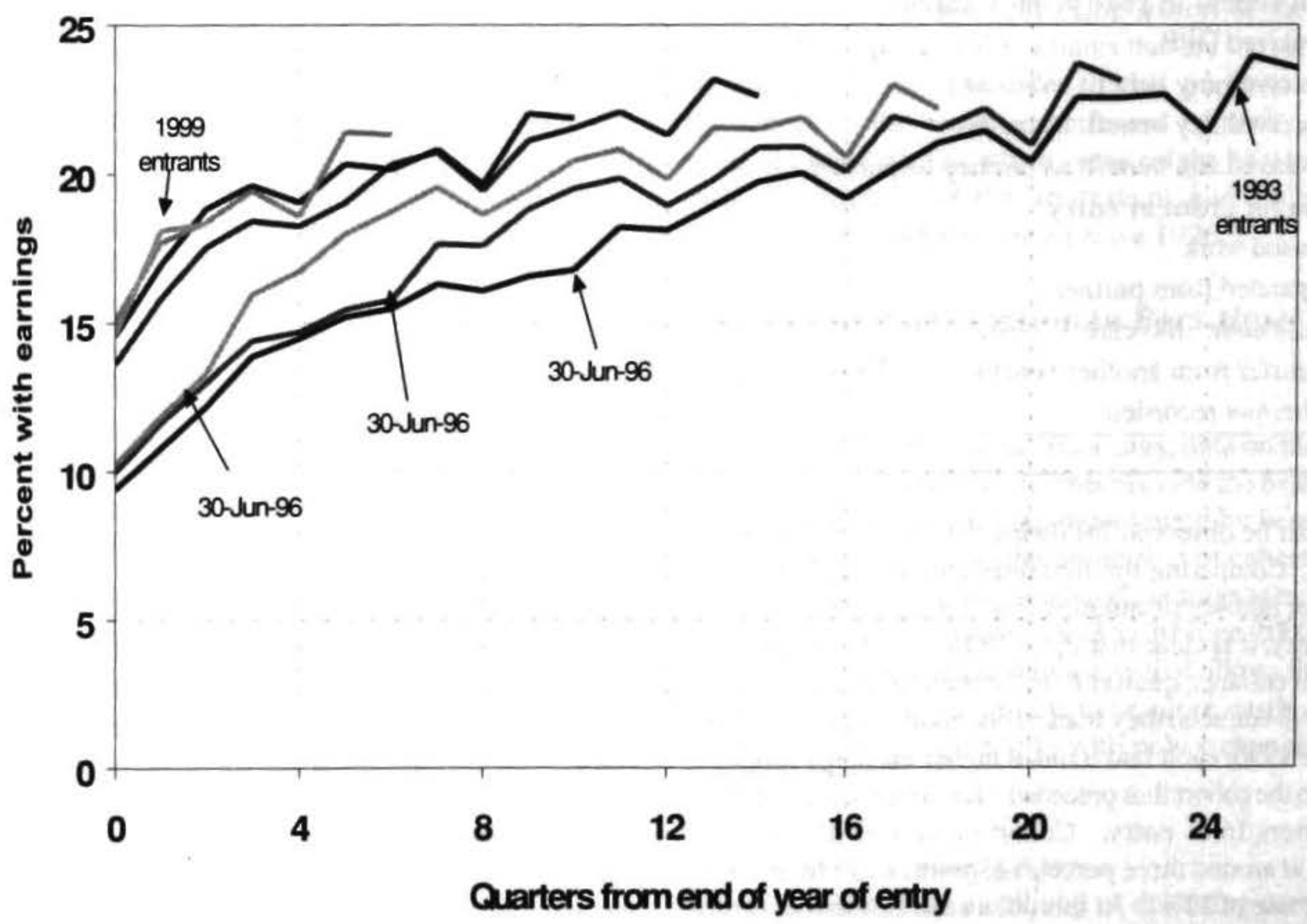


those for the 1993, 1994 and 1995 cohorts at the same duration.

A useful summary measure of the size of the change is the difference between the change in earnings propensities for cohorts as they passed the date of the policy change and the change in earnings propensities for earlier cohorts as they passed the same duration from entry. Table 4 provides such a measure of 'difference in differences'. It shows three results: the average annual percentage change in earnings propensities in the year to 30 June 1997 (4 quarters after the policy change) for the 1994 and 1995 entry cohorts (A); the average annual percentage change in earnings propensities at the same duration from entry for each cohort's predecessor (B) and the ratio of these two measures (A/B).

A year after the policy change, the 1994 and 1995 cohorts of sole parent entrants to DPB had, on average, experienced an annual rate of growth in earnings propensities twice that experienced by their predecessors at the same duration from entry.

Comparing the size of this difference in differences between sub-groups shows a greater change in earnings propensities for sole parent entrants with a youngest child aged 7 or over at entry than for those with younger children. This may reflect the limiting effect of childcare costs and availability on the responsiveness of parents of younger children to the changed incentives. It may also partly reflect the first-quarter impact of the new reciprocal obligations, which began their roll-out on 1 April 1997, and would be expected to be associated with a larger change in behaviour for those with older children (see below).

Comparing the size of this difference in differences between ethnic groups shows a much more modest change for Maori than for members of other ethnic groups. This may partly reflect the greater representation of Maori among cohort members with younger children at entry and the greater childcare barriers to employment faced by that group. Maori recipients of DPB are also less likely than non-Maori to have formal qualifications (Statistics New Zealand unpublished Census tables) and more likely to live in areas with high rates of unemployment which may have affected their ability to find jobs in response to the policy change. Further analysis would be needed to establish, where possible, the independent effects of these factors in explaining differences between Maori and nonMaori.

The shifts in declared earnings propensities following 1 July 1996 are consistent with the expected effects of the new abatement regime on DPB recipients' participation in part-time employment.

\section{April 1997 - New Reciprocal Obligations}

The new reciprocal obligations introduced as part of the response to the ETF were expected to result in a stronger impact on participation in part-time employment than could be achieved by financial incentives alone. As the reciprocal obligations rolled out from 1 April 1997, a further increase in the likelihood of having declared earnings was expected for those with a youngest child aged 14 or over (subject to the part-time work test) and those with a youngest child aged 7 to 13 (subject to the annual planning interview requirement), but not for those with younger children (subject to no new reciprocal obligations).

Figures 3 and 4 show changes in the likelihood of declaring earnings for these sub-groups, defined by the age of the youngest child at entry. Those with a youngest child

\section{Table 4. Average Annual Percentage Change in Earnings Propensities at 30 June 1997 for the 1994 and 1995 Cohorts Observed Passing through the 1 July 1996 Abatement Change and for Preceding Cohorts at the Same Durations from Entry}

\begin{tabular}{lccc}
\hline & $\begin{array}{c}\text { A } \\
\text { Average annual \% change in } \\
\text { earnings propensities in year } \\
\text { to 30 June 1997 for the 1994 } \\
\text { and 1995 cohorts observed } \\
\text { passing through 1 July 1996 } \\
\text { policy change }\end{array}$ & $\begin{array}{c}\text { B } \\
\text { Average annual \% change in } \\
\text { earnings propensities for } \\
\text { preceding cohorts at the same } \\
\text { durations from entry }\end{array}$ & $\begin{array}{c}\text { Ratio } \\
\text { (A/B) }\end{array}$ \\
& 32 & 15 & 2.2 \\
\hline All Sole Parent entrants & & 20 & 1.9 \\
Age of youngest at entry & 36 & 7 & 3.9 \\
0-6 & 28 & 7 & 3.8 \\
$7-13$ & 26 & 25 & 1.6 \\
14 and over & & 23 & 2.6 \\
Ethnicity & 41 & 11 & 2.5 \\
Maori & 60 & & \\
Pacific & 29 & & \\
NZ and other European & & & \\
\hline
\end{tabular}


Figure 3. Percentage of Cohort Members on DPB Declaring Earned Income at Quarterly Intervals, 1993-1999 Entry Cohorts,

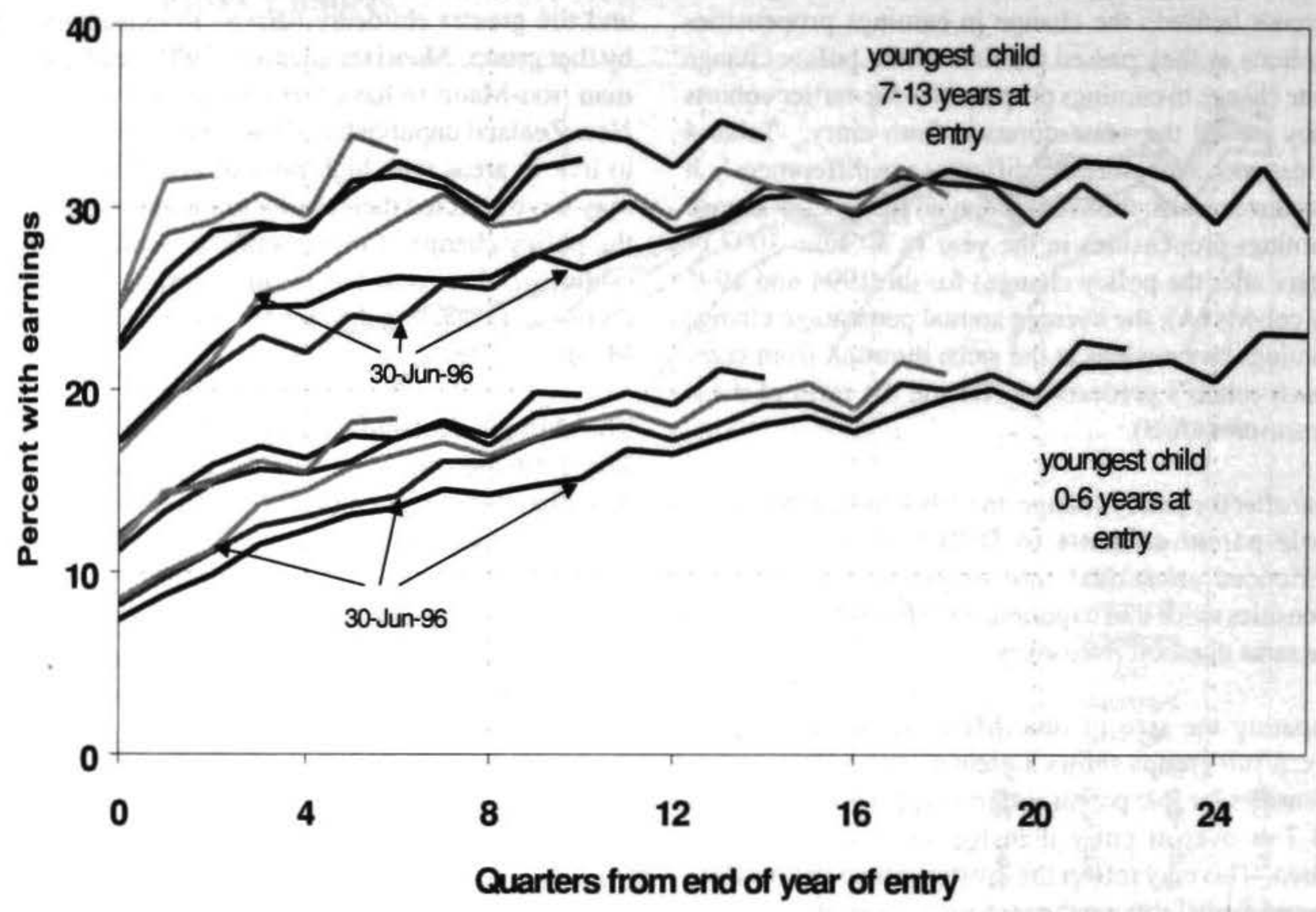

Figure 4. Percentage of Cohort Members on DPB Declaring Earned Income at Quarterly Intervals, 1993-1999 Entry Cohorts with a Youngest Child Aged 14 or Over at Entry

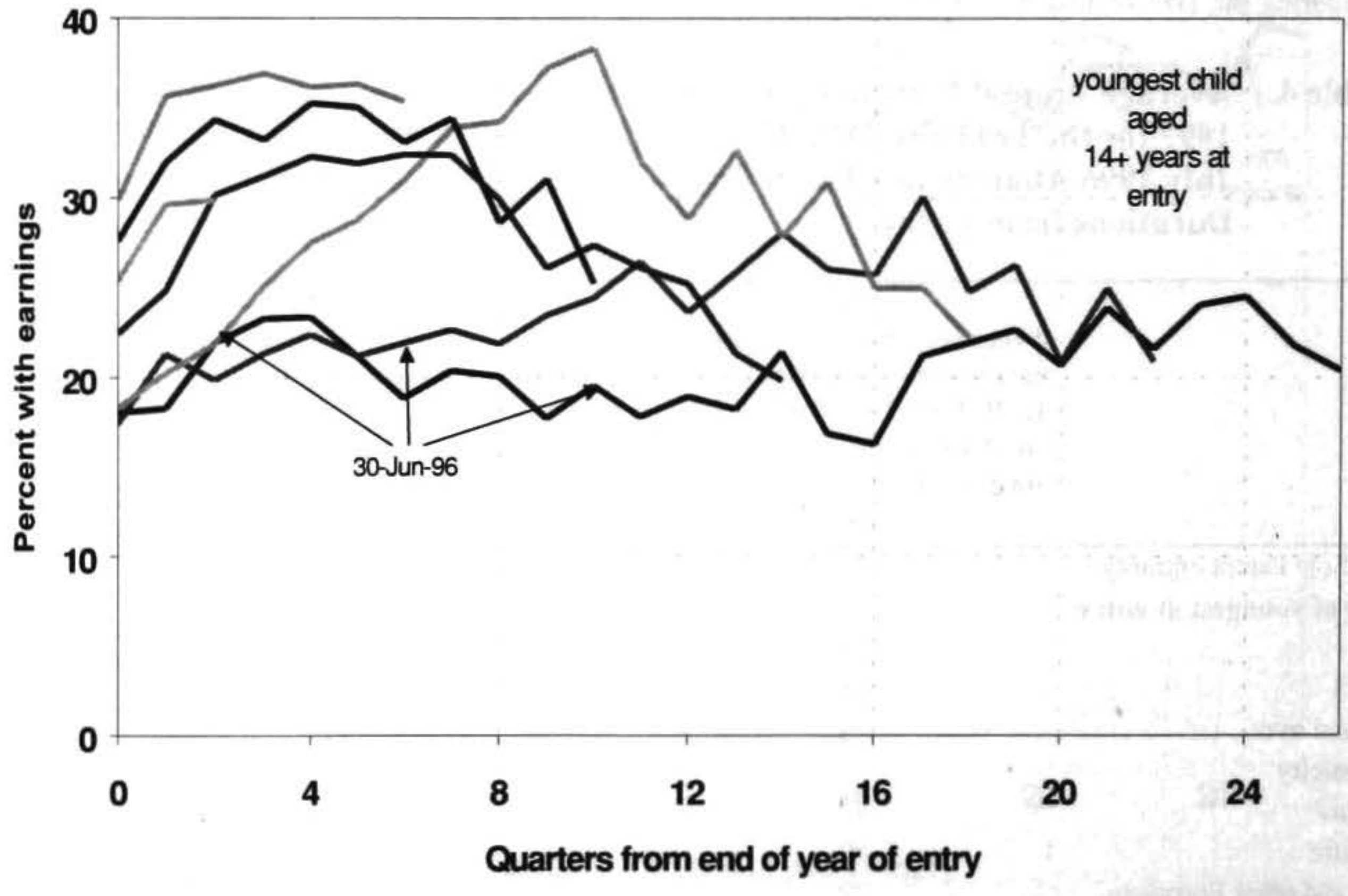




\section{Table 5. Growth in Earnings Propensities Experienced by the 1995 Cohort over the Two Year Period June 1996 - June 1998 Compared with that Experienced by the 1993 Cohort at the Same Duration from Entry}

\begin{tabular}{|c|c|c|c|c|c|c|c|}
\hline & \multicolumn{3}{|c|}{$\begin{array}{l}\text { Percentage change in earnings } \\
\text { propensities for } 1995 \text { cohort over } \\
\text { the period of the ETF changes }\end{array}$} & \multicolumn{3}{|c|}{$\begin{array}{l}\text { Percentage change in earnings } \\
\text { propensities for } 1993 \text { cohort at the } \\
\text { same duration from entry }\end{array}$} & \multirow{2}{*}{$\begin{array}{l}\text { Ratio of } \\
\text { differences } \\
\text { (A/B) }\end{array}$} \\
\hline & $\begin{array}{c}\text { Jun96- } \\
\text { Jun98 }\end{array}$ & $\begin{array}{l}\text { Jun96- } \\
\text { Jun97 }\end{array}$ & $\begin{array}{c}\text { Difference } \\
\mathrm{A}\end{array}$ & $\begin{array}{c}\text { Jun94- } \\
\text { Jun96 }\end{array}$ & $\begin{array}{l}\text { Jun94- } \\
\text { Jun95 }\end{array}$ & $\begin{array}{c}\text { Difference } \\
\text { B } \\
\end{array}$ & \\
\hline All Sole Parent entrants & 54 & 41 & 13 & 38 & 27 & 11 & 1.2 \\
\hline \multicolumn{8}{|l|}{ Age of youngest at entry } \\
\hline $0-6$ & 63 & 46 & 16 & 54 & 37 & 17 & 1.0 \\
\hline $7-13$ & 43 & 36 & 7 & 19 & 17 & 2 & 3.1 \\
\hline $14+$ & 75 & 42 & 34 & -11 & -14 & 3 & 10.7 \\
\hline
\end{tabular}

aged 0-6 at entry (Figure 3 ) show a similar pattern to that observed for all entrants (see Figure 2): marked cohort on-cohort departures in earnings propensities began at the September 1996 quarter and peaked at the June 1997 quarter before narrowing.

The patterns for the older age-of-youngest-child subgroups are less regular. However, if we compare the experiences of the 1993 and 1995 cohorts, it is apparent that the departures in earnings propensities following 1 July 1996 are sustained well beyond June 1997. Table 5 compares the additional growth in earnings propensities experienced by the 1995 cohort in the second half of the two year period following 1 July 1996 (A) with that experienced by the 1993 cohort at the same durations from entry, but prior to the introduction of the ETF reforms (B), across the age-of-youngest-child groups. For entrants with a youngest child aged under 6 , the additional earnings growth experienced in the second half of the two year period was similar for the 1995 and 1993 cohorts. For those with older children at entry who were subject to the new obligations, the 1995 cohort experienced greater earnings growth over this period. Those with children aged 14 or over show the widest margin between the experiences of the 1995 and 1993 cohorts.

These differences are consistent with the expected effects of the ETF reciprocal obligations.

\section{February 1999 - Strengthened and Extended \\ Reciprocal Obligations and Abatement Change}

From February 1999, reciprocal obligations were strengthened for those with a youngest child aged 7 or over and newly extended to those with younger children. The parttime work test that was rolled out to those with a youngest child aged 6-13 was expected to increase the likelihood of those on benefit participating in part-time work. The annual planning interviews and work preparation activities which newly applied at younger ages were also expected to have this effect, but the scale of the response was expected to be more modest.

A full-time work-test now applied to those with a young- est child aged 14 or over who did not qualify for deferral, and those subject to this test were transferred to a steeper abatement regime that provides incentives for full-time work but disincentives for part-time work. Any change in the likelihood of having declared earnings while on benefit for this group could reflect the net effect of a number of different, and potentially offsetting, responses. For example: the strengthened work-test might have encouraged some recipients to newly participate in employment while on benefit; increased abatement might have discouraged some recipients from participating in employment while on benefit; increased abatement might have caused some recipients already combining benefit and employment to lose benefit entitlement; the strengthened work test might have encouraged movement off benefit. If recipients with earnings already were more likely to move this would leave a residual group with lower average earnings propensities.

Figure 2 suggests that if any change in the earnings propensities of cohort members receiving DPB occurred as a result of the DPB Review changes, they do not show up as marked differences between the cohorts overall. Figure 3 shows no marked change for entrants with youngest children aged 0-6 and 7-13 at entry. There were slightly more pronounced than usual peaks in earnings propensities at March 1999 for most cohorts. However, over the year to December 1999, each cohort experienced slower growth in earnings propensities, on average, than that experienced by its predecessor over the year to December 1998.

It is possible that little change in part-time employment occurred as a result of the February 1999 changes for these younger age-of-youngest-child groups. An alternative explanation is that a change in the composition of the groups remaining on DPB offset any behavioural changes that occurred. In Section 4 we find a marked shift in the probability of being off benefit following the February 1999 changes. Those already in part-time employment may have been more likely to leave benefit at this time. We should also note that lags in the collection of income information from DPB recipients make earnings data less 
reliable for the latter part of 1999 and this may also be influencing the findings.

For entrants with children aged 14 or over the proportion declaring earnings declined, on average, for cohorts passing through the February 1999 changes, compared to an increase, on average for preceding cohorts at the same duration from entry (Figure 4). It is not clear without further analysis of individual transitions whether this reflects the effects of the compositional changes hypothesised above, or changes in behaviour consistent with earnings disincentives.

\section{Other Explanations for Declared Earnings Changes $\mathrm{Ob}$ - served}

It is important to note that there are other explanations for the observed shifts in declared earnings propensities.

It is possible that part of the increase in earnings propensities that occurred around the time of the ETF reforms is more apparent than real. The ETF abatement change lowered the financial penalty attached to declaring income and this may have increased the proportion of benefit recipients making truthful earnings declarations. Reciprocal obligations, by placing work expectations on DPB recipients and/or increasing the frequency of their contact with case managers, may also have resulted in previously undeclared earnings being reported.

Changes in the economy may have played a role. The growth in declared earnings propensities that followed the ETF abatement change may be partly explained by a general expansion in part-time employment. HLFS data shows that the annual rate of growth in the proportion of the female working-age population employed part-time did increase over that period, averaging just under one percentage point (or 4\%) in the four quarters to June 1997. A general expansion in part-time employment does not appear to account for changes observed after the 1 April 1997 introduction of reciprocal obligations: the proportion of the female working-aged population employed parttime fell between March 1997 and March 1998. The slowing of growth in part-time employment in 1999 may, however, partly explain the slower rate of growth in declared earning following the DPB Review changes.

Other policy changes may have played a role. Both the ETF and DPB Review changes to abatement and reciprocal obligations were accompanied by a host of other changes. These included changes in case management, changes to welfare to work facilitative measures, increased childcare assistance, increased rates of family assistance, and reductions in tax rates all aimed at increasing movement families into work. The 1998 benefit fraud campaign accompanied the announcement of the DPB Review changes, and an IRD campaign aimed at raising awareness of in-work family assistance accompanied their introduction. These events may account for some of the differences between cohorts.

The shifts in earnings observed are unlikely to be explained by demographic changes however. While differences in the age structure of the parents and children in successive cohorts are likely to partly account for the small cohorton-cohort increases in earnings propensities observed over the study period as a whole (see Figure 2), by their nature, we would not expect these differences to result in a large change in behaviour affecting all cohorts at the same point in calendar time.

While other factors are likely to have played a role, the magnitude and timing of the changes that immediately followed the ETF reforms, and the contrasting experiences of sub-groups affected in different ways by the ETF reciprocal obligations, suggests that these were largely the result of the policy changes rather than the economic, administrative and demographic changes that coincided with them.

\section{Changes in Participation in Full-time Employment}

The best proxy for full-time employment available from benefit dynamics data is non-receipt of benefit income. Although information on destinations at the end of spells on benefit and events that led to their commencement is collected, the rate of non-recording is high, and it is likely that neither measure accurately reflects the real extent of full-time employment between spells on benefit. In addition, information on hours of work, which would be needed to assess the extent of full-time employment while in receipt of DPB, is not collected. Non-receipt has its limitations as a measure of the possible full-time employment outcomes of policy changes however. Many people leave DPB for reasons other than full-time employment, the prime one being partnering. Changes in partnering propensities, and changes in couples' propensities to be off benefit, will therefore impact on our measure.

Wilson (2000) explored possible links between the ETF abatement and reciprocal obligations reforms and changes in benefit receipt. During the period when the immediate effects of those reforms might have been expected to be felt, changes in the probability of benefit receipt were not marked. In this section, we examine changes in benefit receipt around the time of the February 1999 introduction of the DPB Review changes. Unlike the ETF reforms, the DPB Review changes were aimed at making an immediate impact on participation in full-time work and so we might expect to see more marked differences following their introduction.

\section{February 1999 - Strengthened and Extended Reciprocal Obligations and Abatement Change} Figure 5 shows changes in the cohorts' probabilities of not being in receipt of DPB. Note that this captures changes both in the rate of exit from DPB, and in the rate of return to that benefit. The cohorts track one another relatively closely in the early part of the study but in the last two years clear cohort-on-cohort differences emerge. Members of each cohort were less likely to be on DPB 


\section{Figure 5. Percentage of Cohort Members Not on DPB at Quarterly Intervals, 1993-1999 Entry Cohorts}

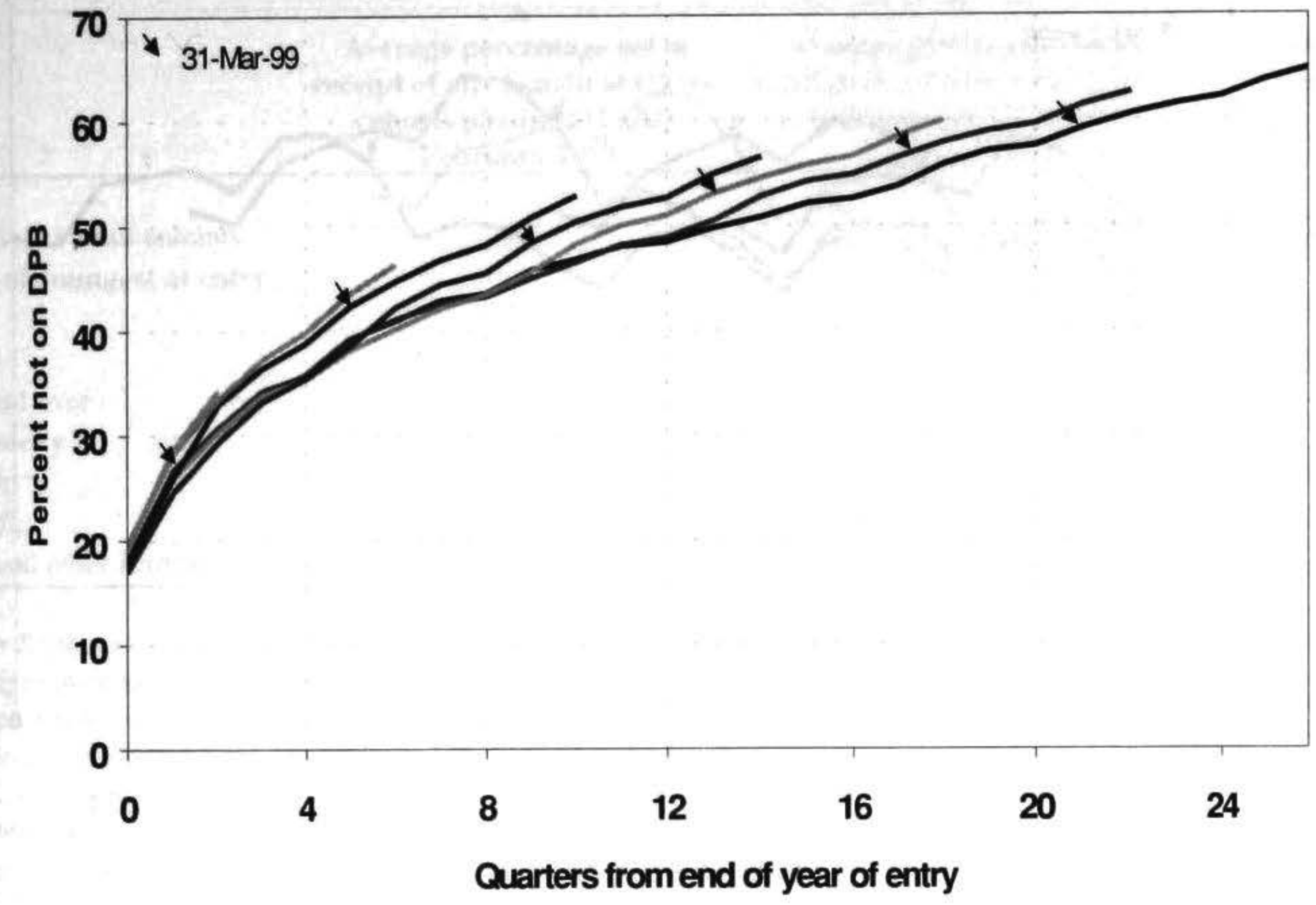

than their predecessors after the February 1999 reforms. The differences between cohorts had emerged in mid1998, well before the reforms.

Figure 6 shows that much of the increase in the likelihood of being off DPB that occurred in 1998 was associated with a sharp increase in the proportion of cohort members on benefit as a partner from the June 1998 quarter. This appears consistent with increased declaration of partnerships as a result of the benefit fraud advertising campaign which ran between April and June 1998. The existence of this shift makes it difficult to isolate changes that might be consistent with policy impacts.

Figure 7 shows changes in an alternative measure which avoids the complicating effects of the 1998 shifts in receipt. It shows the cohorts' probabilities of not being in receipt of any main benefit, either as a primary recipient or as a partner. Again, this measure takes account of changes in both the probability of exit and the probability of return. When we examine non-receipt on this basis, marked cohort-on-cohort differences do not generally emerge until after the February 1999 changes. For the 1994-1996 cohorts, cohort-on-cohort differences began in the March 1999 quarter. For the 1997 cohort, a marked departure from the pattern followed by earlier cohorts was apparent at June 1998, and widened from the March 1999 quarter. The 1998 and 1999 cohorts of entrants whom we follow only after the introduction of the DPB Review changes had the highest probabilities of being not in receipt of benefit.

Are these changes consistent with the expected effects of the DPB Review changes on participation in full-time employment? Table 6 compares the average percentage of cohort members not in receipt of any benefit two quarters from the end of their year of entry across differentage-of youngest-child sub-groups. Overall, the average probability of being off benefit at two quarters (or 30 June of the year following their entry to benefit) was 3 percentage points higher for cohorts passing this point after February 1999 ( 25 percent compared with 22 percent for preceding cohorts), an increase of 14 percent. The size of the increase was greatest for those with a youngest child aged 14 or over at entry. This is consistent with the expected policy impacts.

However, the increase in non-receipt was also pronounced for those with younger children not targeted by the fulltime work-test. The reforms may have had a signalling effect which led to wider changes in full-time employment propensities than expected. Or the referrals and assistance received as a result of planning interviews and part-time work testing may have assisted people wanting to move into full-time work to make the transition. This is unlikely to explain all of the shift however. Other factors are likely to explain much of the reduction in benefit receipt. 
Figure 6. Percentage of Cohort Members on Benefit as a Partner at Quarterly Intervals, 1993-1999 Entry Cohorts

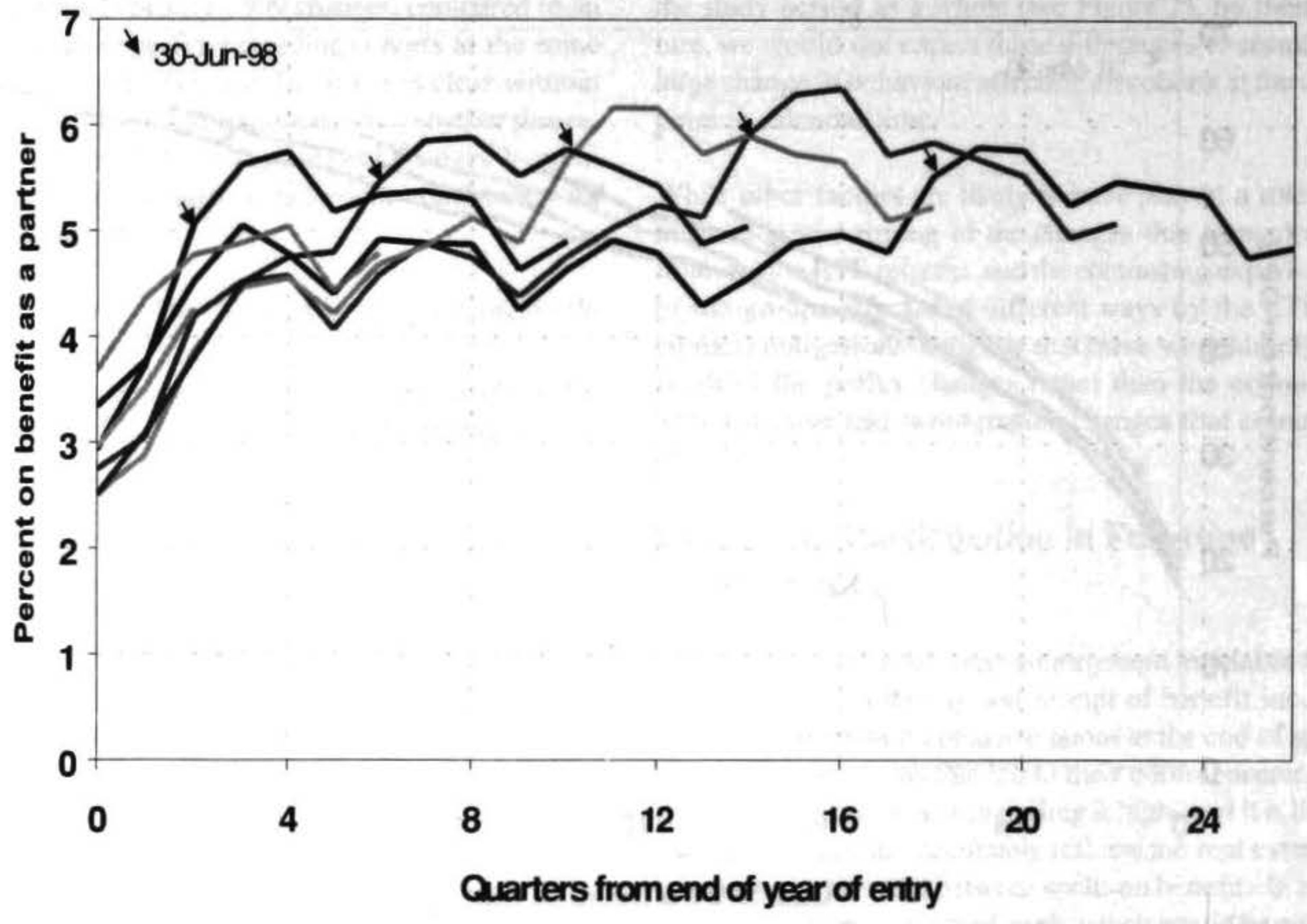

Figure 7. Percentage of Cohort Members Not on Any Benefit Either as Primary or Partner at Quarterly Intervals, 1993-1999 Entry Cohorts

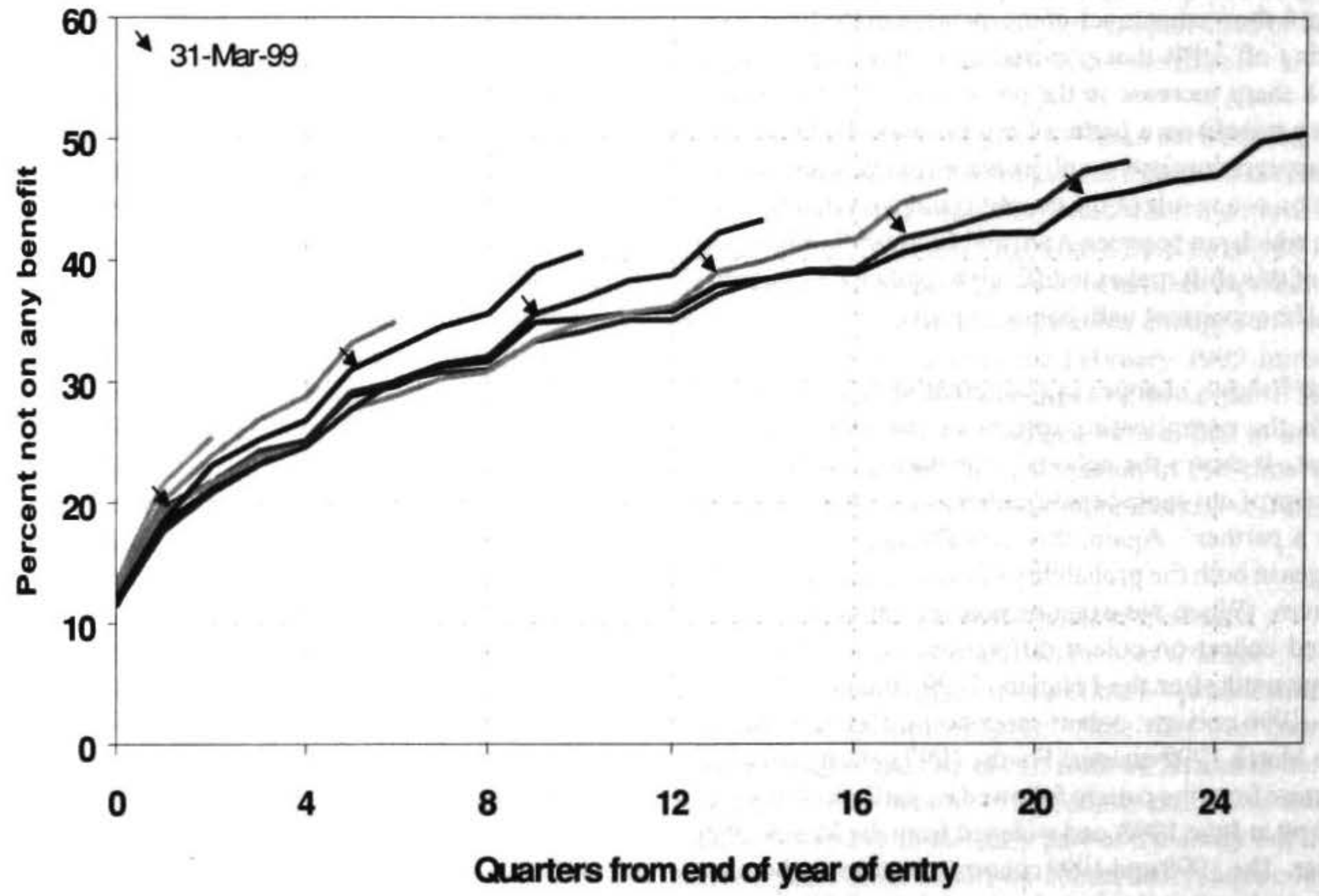




\section{Table 6. Change in Percentage Not in Receipt of Any Benefit at Two Quarters from the End of the Year of Entry - Averages for Cohorts Reaching Two Quarters Before and After the February 1999 Policy Change}

\begin{tabular}{lccc}
\hline & $\begin{array}{c}\text { A } \\
\text { Average percentage not in } \\
\text { receipt of any benefit at Q2 for } \\
\text { cohorts passing Q2 after } \\
\text { February 1999 }\end{array}$ & $\begin{array}{c}\text { B } \\
\text { Average percentage not in } \\
\text { receipt of any benefit at Q2 for } \\
\text { cohorts passing Q2 prior to } \\
\text { February 1999 }\end{array}$ & $\begin{array}{c}\text { Ratio } \\
\text { (A/B) }\end{array}$ \\
\hline All Sole Parent entrants & 25 & 22 & 1.14 \\
Age of youngest at entry & & & \\
$0-6$ & 22 & 20 & 1.12 \\
$7-13$ & 30 & 26 & 1.15 \\
14 and over & 38 & 33 & 1.17 \\
Ethnicity & & & 1.28 \\
Maori & 20 & 15 & 1.15 \\
Pacific & 25 & 21 & 1.17 \\
NZ and other European & 28 & 24 & \\
\hline
\end{tabular}

Other Explanations for Changes in Non-receipt Observed Changes in employment conditions appear likely to have played a role. HLFS data show an increase in full-time employment propensities for partnered as well as sole mothers between the December 1998 and December 1999 quarters. This suggests that some of the reduction in cohort members' benefit receipt over that period may have been due to improved opportunities for full-time work among women with dependent children more generally.

Any improvement in male employment rates might also have had the effect of reducing cohort members' benefit receipt, both by increasing the employment rates of sole fathers, and by reducing the likelihood that sole mothers who left DPB as a result of partnering remained on benefit. HLFS data show that full-time employment propensities of partnered fathers dipped in the quarter following the February 1999 policy change, but rose over most of the ensuing year. The reduction in the likelihood of cohort members being on benefit as a partner from mid1999 (Figure 6), and the rise in non-receipt overall over that period (Figure 7) is likely to partly reflect this improvement.

The HLFS also records faster growth in full-time employment propensities for Maori men and women than nonMaori men and women over the period. The larger reduction in benefit receipt for Maori than for European and Pacific cohort members following February 1999 shown in Table 6 may partly reflect this.

Other policy events could also have contributed to the shift in non-receipt observed.

A subsidy for the costs of after school and school holiday care (the OSCAR subsidy) was introduced as part of the wider DPB Review package of reforms. This may have assisted some sole parents with children in the eligible age range (5-13 years) to take up full-time employment.
Other facilitative measures introduced as part of the DPB Review may have also assisted people with younger children into full-time paid work.

An Inland Revenue Department advertising campaign promoting in work family assistance coincided with the February 1999 introduction of the DPB Review change. The campaign may have increased the level of income that sole parents and couples in receipt of benefit perceived they would receive on moving into full-time work.

At the beginning of 1999 , new rules re-focussing eligibility to the Training Incentive Allowance (TIA) in line with the new work expectations, introducing more work focussed case management to determine eligibility to the payment, and increasing the contribution to costs required of some course participants also came into effect. These changes led to lower take-up of TIA and are likely to have reduced DPB recipients' participation in education and training. This may have increased availability for employment.

It is possible that by 1999 , the longer-term effects on fulltime employment propensities sought by the ETF changes were beginning to become apparent. To the extent that the ETF changes increased participation in part-time employment, and to the extent that this led to higher fulltime earnings propensities, they may, together with the tax cuts, and changes to Family Assistance that occurred over the period, have raised the in-work incomes of sole parents leaving benefit for work or relationships, and led to more sustained exits.

The proximity of policy events, and the combination of long-term and immediate possible policy impacts, is likely to make statistical analysis to isolate the impact of the DPB Review reforms problematic. 


\section{Conclusion}

This paper uses benefit dynamics data to examine patterns of benefit use by successive cohorts of sole parent entrants to the DPB as they passed through the period of the ETF and DPB Review changes to reciprocal obligations and benefit abatement.

It finds large changes in the propensity to declare earnings following the ETF reforms that are consistent with their expected impacts on participation in part-time employment. The magnitude and timing of the changes, and the contrasting experiences of sub-groups affected in different ways by the ETF reciprocal obligations, suggests that these changes were largely the result of the policy changes rather than the economic, administrative and demographic changes that coincided with them.

Links between the DPB Review changes and changes in the declared earnings of those on DPB are less clear. Aside from a small shift in the first quarter immediately following the introduction of the changes, we do not see marked increase in earnings propensities. Further work is needed to assess whether a higher rate of exit from benefit among those already in part-time work masks a greater change. The DPB Review changes were followed by a marked increase in cohort members' likelihood of being off benefit. The scale of the increase when measured 2 quarters from the end of the year of entry was greatest for entrants with a youngest child aged 14 or over subject to a fulltime work test which is consistent with the expected policy impacts. However, the increase in non-receipt was also marked for those with younger children which suggests that other factors, including other policy changes as well as general improvements in employment rates, are likely to also partly account for the change.

Qualitative and quantitative evaluations of the DPB Review reforms currently underway will enhance our understanding of the individual experiences of the reforms and our appreciation of the extent to which the reforms can account for the changes in benefit receipt that have accompanied them. The evaluations will also seek to answer important questions that cannot be addressed using benefit dynamics data: how did the reforms impact on parents' abilities to meet their care, control and support responsibilities, and what was the impact of the reforms on children in the families affected?

\section{Future Research}

The analysis presented here provides a high level exploration of changes in patterns of receipt that might be consistent with policy impacts. Multivariate analysis to estimate the size of the impact of the ETF changes on parttime employment propensities, controlling for other factors, is an option for future research. The complexity of the policy environment that surrounded the February 1999 changes suggests that even with multivariate analysis we will be unable to arrive at an estimate of the impact of the
DPB Review changes.

Further analysis of the individual transitions behind the overall patterns observed could also improve our understanding of the changes that have occurred. For example, were those who already participated in part-time employment more likely than those who didn't to move off benefit following the February 1999 changes? And could compositional shifts therefore explain the absence of a more marked increase in earnings propensities for those on benefit?

\section{Notes}

1 We would like to thank Ron Lovell, Simon Chapple, John Jensen and Mike Rochford for their helpful comments on this paper. The views expressed are not necessarily those of the Ministry of Social Policy.

2 DPB is an income-tested benefit payable to sole parents. It can also be paid to those providing full-time care for a sick or infirm person ("carers") and older single women without dependent children ("women alone"). This paper only examines sole parent recipients of the benefit.

3 Reciprocal obligations were also introduced for women alone and carers receiving DPB and some partners of unemployment benefit recipients.

4 Reciprocal obligations were also strengthened for and/or extended to women alone and carers receiving DPB and partners of recipients of all other working age benefits. The abatement change also applied to women alone receiving DPB.

5 This entailed an increase in the abatement rate applying to additional income between $\$ 81$ and $\$ 180$ per week from $30 \%$ to $70 \%$.

6 See Wilson (1999) for a description of benefit dynamics data.

7 The cohorts include all sole parents granted DPB in a given calendar year and are not confined to first ever entries into the benefit system. A person can therefore appear in more than one cohort if they had grants in more than one calendar year. Data for years prior to 1993 are not sufficiently robust to be included in the benefit dynamics data set, and for this reason it is not possible to examine the experiences of earlier entry cohorts. Members of the seven entry cohorts that can be studied made up $44 \%$ of all sole parents in receipt of DPB on 31 December 1994 and $86 \%$ of sole parents in receipt on 31 December 1999. Those who received benefit at these dates but are excluded from the analysis are earlier entrants who received DPB continuously throughout the study period (very long-term DPB recipients) or ceased receiving DPB within the study period and did not return.

8 These data require some caution in interpretation. See Wilson (2000).

9 Note that it is possible to work full-time and still be in 
receipt of DPB if the recipient still meets the income

test after any income is taken into account. In the absence of information on hours of work it is not possible to identify cases where this occurs.

10 Defined as the proportion of cohort members in receipt of DPB who had declared earnings.

11 In some cases information on actual income is not collected until the annual renewal of benefit. This means that earnings data for the latter part of 1999 will not be fully complete until the end of 2000 . This may influence the comparison, but given that the current analysis was based on data extracted at 31 October 2000, it is unlikely to change the conclusions for the March, June and September quarters following the introduction of the February 1999 changes.

11 See Wilson (2000) for a chronology of these events.

12 Some could still receive supplementary assistance, such as the Accommodation Supplement, as non-beneficiaries.

14 For all but quarter 0 for the 1998 cohort.

\title{
References
}

Goodger, K. and Larose, P. (1999) Changing Expectations: Sole Parents and Employment in New Zealand. Social Policy Journal of New Zealand. (12): 53-70.

Wilson, M. (1999) The Duration of Benefit Receipt: New Findings from the Benefit Dynamics Data Set. Social Policy Journal of New Zealand. (13): 59-82.

Wilson, M. (2000) The Policy Response to the Employment Task Force and Changing Patterns of Domestic Purposes Benefit Receipt: A Cohort Analysis.

Social Policy Journal of New Zealand. (14): 78-103.

\section{Authors}

\section{Moira Wilson}

Senior Research Analyst

Information and Analysis Group

Ministry of Social Policy

Private Bag 39993

Wellington

moira.wilson@dsw.govt.nz

\author{
Deborah Ball \\ Research Analyst \\ Information and Analysis Group \\ Ministry of Social Policy \\ Private Bag 39993 \\ Wellington \\ deborah.balloo2.mosp.govt.nz
}

